\title{
Beam Induced Modification of Polysilane For Fine Pattern Generation
}

\author{
Masataka HIROSE, Katsuhiko OKAMOTO and Seiichi MIYAZAKI \\ Department of Electrical Engineering Hiroshima University
}

Higashi-Hiroshima 724, JAPAN

\begin{abstract}
Polysilane thin films have been grown by the glow discharge of $\mathrm{SiH}_{4}$ gas at a substrate temperature of $-110^{\circ} \mathrm{C}$. The infrared absorption spectra have shown that polysilane $\left(\mathrm{SiH}_{2}\right)_{\mathrm{n}}$ chains are predominantly incorporated in the matrix together with $\mathrm{SiH}_{3}$ which terminates the chain. The bonded hydrogen in the film is effused by electron beam (EB) or ArF eximer laser irradiation, resulting in three-dimensional $\mathrm{Si}$ network formation. An asdeposited polysilane is easily oxidized in air at room temperature, while the beam irradiated region is hardly oxidized. The fine silicon line and pillar of about $0.12 \mu \mathrm{m}$ embedded in $\mathrm{SiO}_{2}$ are formed by irradiating electron beam at an acceleration voltage of $25 \mathrm{kV}$ with a dose of $20 \mathrm{mC} / \mathrm{cm}^{2}$. The silicon pattern is basically in amorphous phase and crystallized by annealing at 800 ${ }^{\circ} \mathrm{C}$. Also, the silicon line of about $1 \mu \mathrm{m}$ is generated by irradiating ArF excimer laser through a conventional mask at a pulse energy of 10 $\mathrm{mJ} \bullet \mathrm{cm}^{-2} / \mathrm{shot}$ with 1000 shots. The generated silicon line is found to be polycrystalline.
\end{abstract}

\section{Introduction}

Resist mask pattern generation by electron beam (EB) lithography or photolithography followed by reactive ion etching of an underlying material is widely used for the fabrication of fine structures. The other approach to directly synthesizing a fine metal pattern is to utilize the EBinduced decomposition of a gold-containing organometallic polymer.[1] Also, spin-on-glass (SOG) which contains triphenylsulfonium triflate $\left(\mathrm{Ph}_{3} \mathrm{~S}^{+} \mathrm{OTf}\right)$ as an acid generator is sensitive to EB irradiation to form $\mathrm{SiO}_{2}$. Thus produced oxide patterns have been used for a bilayer resist[2]. A finc carbon pattern has been deposited by EB-induced decomposition of styrene $\left(\mathrm{C}_{6} \mathrm{H}_{5} \mathrm{CH}=\mathrm{CH}_{2}\right)$ adsorbed on the substrate surface.[3] Also, the low energy plasma induced dehydrogenative polymerization of monosubstituted silanes $\left(\mathrm{RSiH}_{3}\right)$ has been photo-oxidatively patterned with mid- 
deep ultraviolet light producing glasslike Si-O-Si crosslinked materials in exposed areas.[4] Hydrogenated polysilane deposited from a silane plasma at a substrate temperature of $-110^{\circ} \mathrm{C}$ is easily oxidized in air at room temperature.[5] Also, the bonded hydrogen in the film is effused by electron beam irradiation. This results in three-dimensional Si network formation, being possible to be used as an EB sensitive material.[6] Polysilane has also been synthesized either by disilane glow discharge decomposition at a substrate temperature of $-53^{\circ} \mathrm{C}[7]$ or by the homogeneous chemical vapor deposition (HOMOCVD) of silane at room temperature. [8]

In this paper, we describe a novel method to form ultra-fine silicon structures by means of electron or laser beam induced modification of polysilane.

\section{Expremental}

Polysilane films were deposited on quartz and $\mathrm{c}-\mathrm{Si}(100)$ substrates cooled at $-110^{\circ} \mathrm{C}$ by the if glow discharge decomposition of $3 \% \mathrm{SiH}_{4}$ diluted with $\mathrm{H}_{2}$ in a capacitively coupled reactor. [5] The total gas pressure and the rf power density were maintained at 0.4 Torr and $0.26 \mathrm{~W} / \mathrm{cm}^{2}$, respectively. Polysilane was irradiated with EB in a computer-controlled nanolithography system (JEOL JBX$5 \mathrm{DII}$ ), at an acceleration voltage of $25 \mathrm{kV}$ and a current of $500 \mathrm{pA}$ to the total dose range of 10 to 40 $\mathrm{mC} / \mathrm{cm}^{2}$. In order to evaluate the change in the film structure by EB irradiation the polysilane was exposed to EB in a scanning electron microscope (JEOL JSM-820) at an acceleration voltage of 25 $\mathrm{kV}$ and a current density of $0.5 \mu \mathrm{A} / \mathrm{cm}^{2}$ with the total dose range of $\sim 40 \mathrm{mC} / \mathrm{cm}^{2}$. Also, ArF excimer laser beam (193nm) was irradiated to the polysilane film with an energy of $10 \mathrm{or} 20 \mathrm{~mJ} \cdot \mathrm{cm}^{-2} / \mathrm{shot}$ at a repetition rate of $10 \mathrm{~Hz}$ in vacuum. The EB or laser beam induced desorption of bonded hydrogen from polysilane are evaluated by FT-IR (Fourier transform infrared absorption). The threedimensional Si network formation and the crystallization were characterized by Raman scattering and reflection high-energy electron diffraction (RHEED).

\section{Results and Discussion}

\subsection{Characterization of polysilane before and after beam irradiation}

The chemical bonding features of as-deposited and beam-irradiated films are examined by infrared absorption spectroscopy. The spectra due to the hydrogen bond stretching modes indicate that the bonded hydrogen in a polysilane film is effused by EB irradiation as shown in Fig. 1(a). The absorption intensities of $\mathrm{SiH}_{3}$ and $\left(\mathrm{SiH}_{2}\right)_{\mathrm{a}}$ are significantly reduced by EB irradiation. The bonded hydrogen in polysilane is decreased down to about $60 \%$ of the initial value by $12 \mathrm{~min}$ EB irradiation corresponding to a dose of $40 \mathrm{mC} / \mathrm{cm}^{2}$. The effect of ArF excimer laser irradiation on a polysilane film is also shown in Fig. 1(b). It is interesting to note that the change in the hydrogen bonding features by EB irradiation is very similar to the case of laser irradiation. In both cases, hydrogen desorption promotes the three-dimensional $\mathrm{Si}$ network formation in the irradiated region. The 


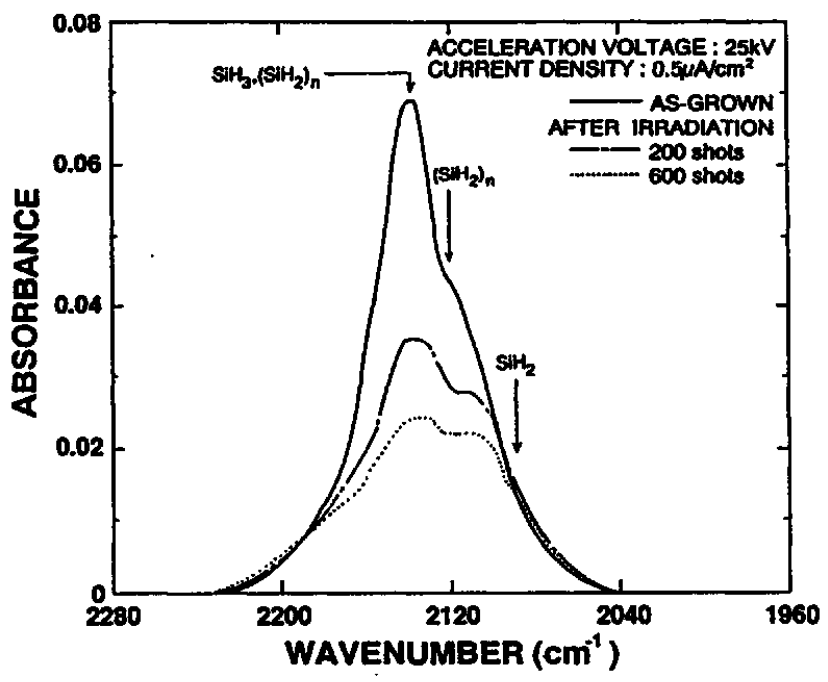

(a)

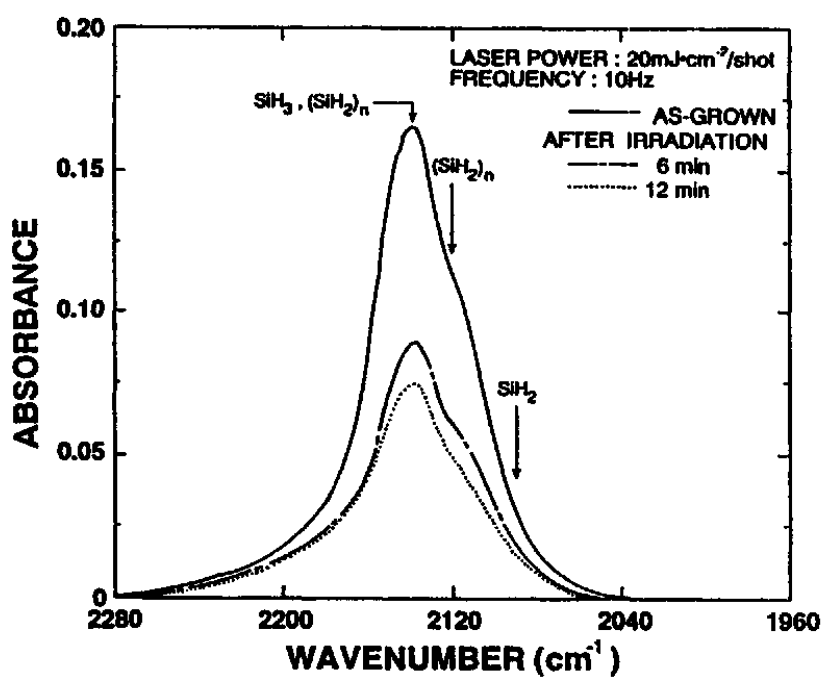

(b)

Fig. 1.Infrared absorption spectra due to the stretching modes of $\operatorname{SiH}_{x}(x=2,3)$ and $\left(\mathrm{SiH}_{2}\right)_{n}$ chains before and after EB irradiation(a) and excimer laser irradiation(b).

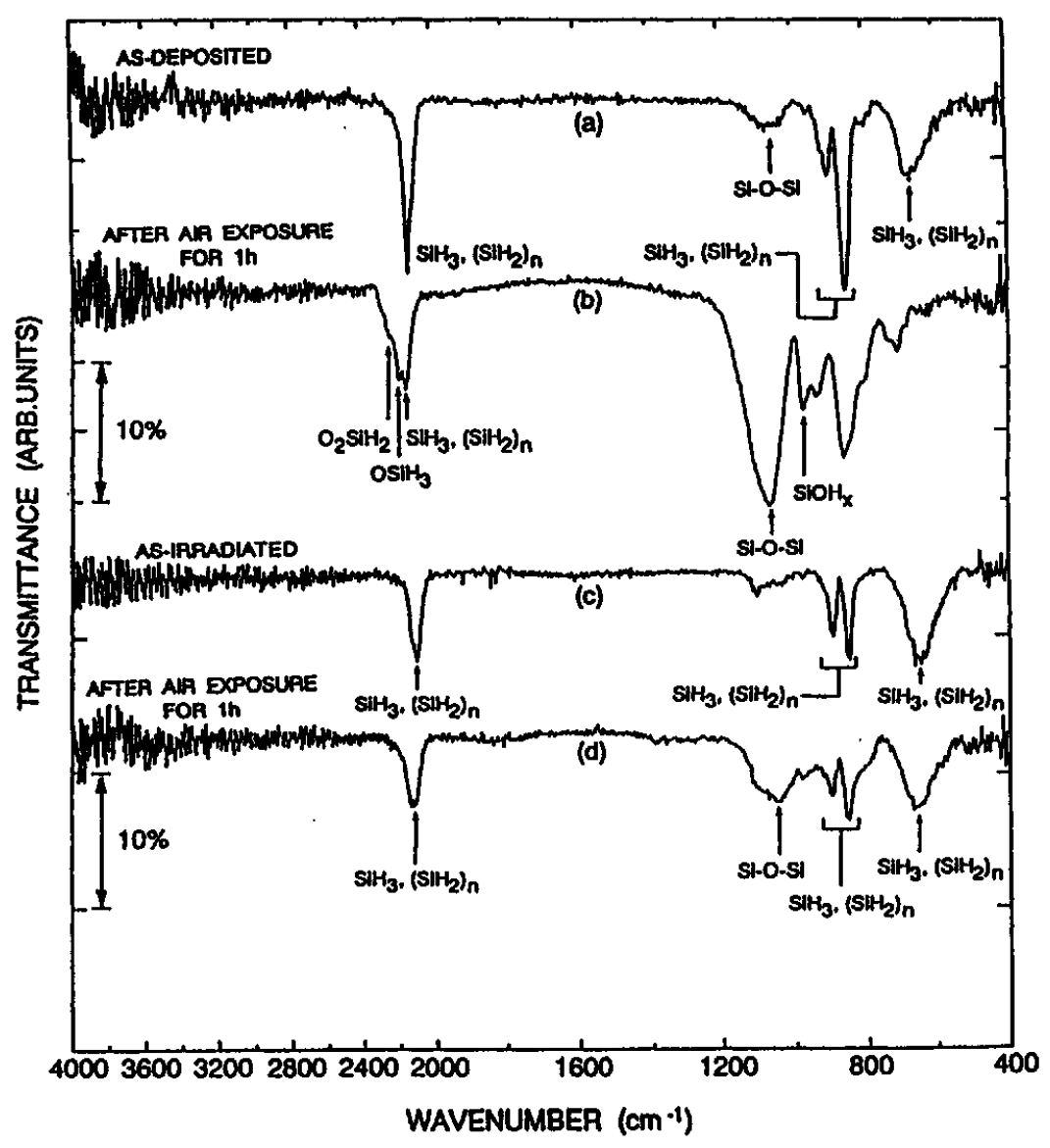

Fig. 2.Infrared absorption spectra of polysilane grown at $-110^{\circ} \mathrm{C}$; (a) as-deposited, (b) after air exposure at room temperature for $1 \mathrm{hr}$, (c) EB-irradiated before air exposure and (d) EB-irradiated after air exposure at room temperature for $1 \mathrm{hr}$. 


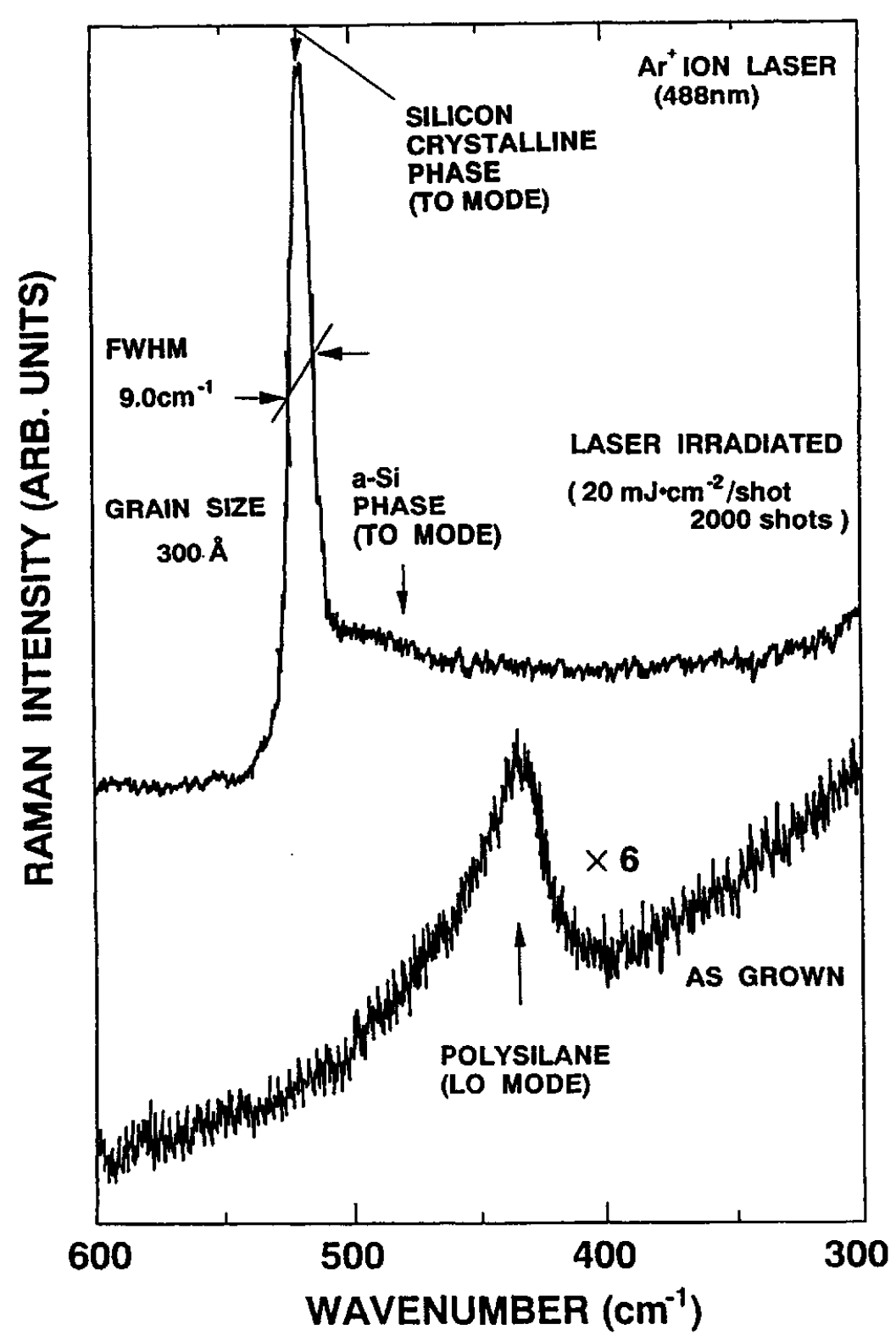

Fig. 3. Raman spectra for as-deposited and laser-irradiated film. The laser energy and the number of laser pulses are $20 \mathrm{~mJ}^{\circ} \mathrm{cm}^{-2} /$ shot and 2000 shots, respectively. A $488 \mathrm{~nm}$ line from an $\mathrm{Ar}^{+}$ion laser was used as an excitation source for Raman scattering.

polysilane film grown at $-110^{\circ} \mathrm{C}$ consists of $\left(\mathrm{SiH}_{2}\right)_{\mathrm{n}}$ chains terminated with $\mathrm{SiH}_{3}$, being easily oxidized in air at room temperature[5] as shown by curve (b) in Fig. 2. The absorption bands due to the Si-O-Si stretching mode at $\sim 1060 \mathrm{~cm}^{-1}$ and the hydrogen bond-stretching modes of $\mathrm{OSiH}_{3}$ at $\sim 2180 \mathrm{~cm}^{-1}$ and $\mathrm{O}_{2} \mathrm{SiH}_{2}$ at $\sim 2230 \mathrm{~cm}^{-1}$ [9] are clearly observable in the figure. The strong absorption of $\mathrm{OSiH}_{3}$ with respect to $\mathrm{O}_{2} \mathrm{SiH}_{2}$ implies that the oxidation tends to occur selectively from the $\mathrm{Si}$ backbond of $\mathrm{SiH}_{3}$ which terminates the $\left(\mathrm{SiH}_{2}\right)_{n}$ chains. It is interesting to note that the polysilane film irradiated by EB at an acceleration voltage of $25 \mathrm{kV}$ and a current density of $50 \mu \mathrm{A} / \mathrm{cm}^{2}$ to a dose 
of $15 \mathrm{mC} / \mathrm{cm}^{2}$ is hardly oxidized at room temperature, as shown by curve (d) in Fig.2, where $\mathrm{O}_{2} \mathrm{SiH}_{2}$ and $\mathrm{OSiH}_{3}$ absorption bands are not observable.

The polysilane film irradiated with ArF excimer laser is also hardly oxidized at room temperature. This is because the three-dimensional Si network formation and crystallization is promoted by laser beam induced hydrogen evolution and the chemical stability of the material is improved. The crystalline Si network formation by the laser beam irradiation is directly confirmed by the Raman spectra for as-deposited and irradiated films as shown in Fig. 3. In an as-deposited film, the observed peak at $\sim 430 \mathrm{~cm}^{-1}$ is attributable to the LO phonon mode of the Si skeleton in long-chain polysilane[10]. The Raman spectrum of the EB irradiated region exhibits a weak, broad peak at $\sim 480 \mathrm{~cm}^{-1}$ originating from the TO mode of a silicon random network such as hydrogenated amorphous silicon (a-Si:H). In contrast to this, after 2000 shots of laser irradiation at a pulse energy of $20 \mathrm{~mJ}^{\circ} \mathrm{cm}^{-2} / \mathrm{shot}$, a sharp, intense peak is clearly observed at $\sim 518 \mathrm{~cm}^{-1}$ arising from the TO mode of crystallized Si together with a weak, broad yield around at $\sim 48 \mathrm{~cm}^{-1}$ that is assigned as the TO phonon mode in amorphous Si network. This difference is attributed to the difference in the energy loss mechanism of electron beam $\left(25 \mathrm{keV}, 50 \mu \mathrm{A} / \mathrm{cm}^{2}\right)$ and UV photons (193 nm) in polysilane. Namely, UV photons are more effectively absorbed in the film surface region than the electron beam. The optical excitation of $\mathrm{Si}-\mathrm{Si}$ and $\mathrm{Si}-\mathrm{H}$ bonds in the metastable polysilane promotes the Si dangling bond formation and corresponding change in $\mathrm{Si}$ atom configurations, leading to the network crystallization. By taking into account the facts that a TO phonon peak at $\sim 520 \mathrm{~cm}^{-1}$ for bulk crystalline Si has a full width at half maximum (FWHM) of $8.3 \mathrm{~cm}^{-1}$ and the observed FWHM of polycrystallized $\mathrm{Si}$ is $\sim 9 \mathrm{~cm}^{-1}$, the FWHM difference gives an average grain size of $\sim 300 \AA$.

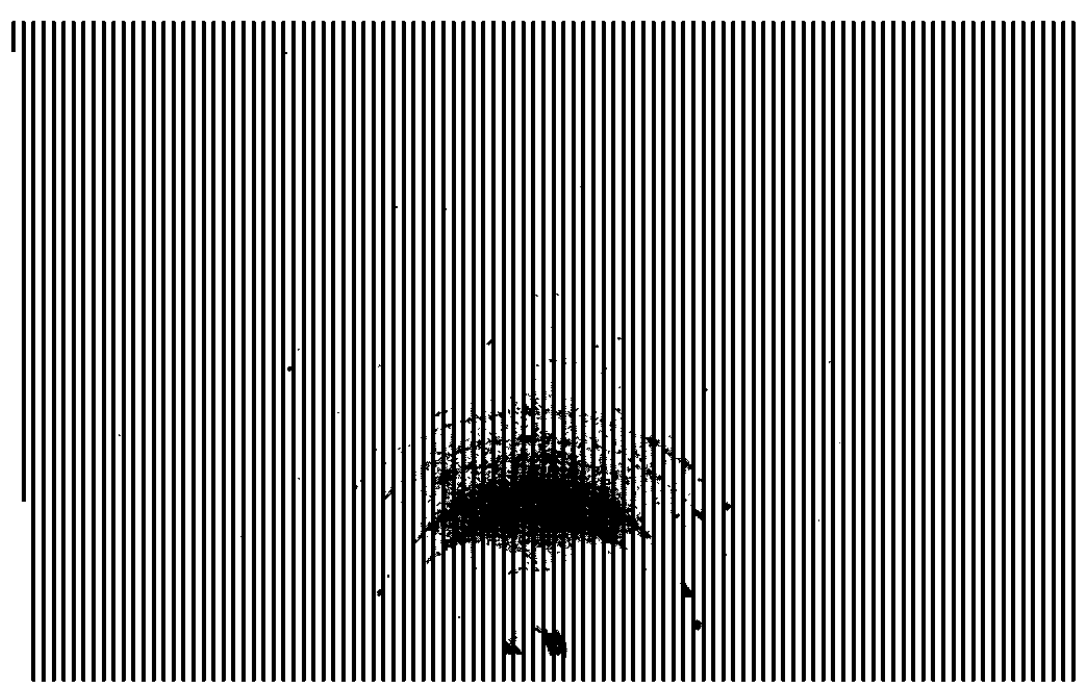

Fig.4. RHEED pattern of a Si line generated by EB from polysilane and annealed at $800^{\circ} \mathrm{C}$. 
Furthermore, the $2 \mathrm{~cm}^{-1}$ red-shift of the TO peak for the laser crystallized film suggests that a tensile stress of $\sim 5 \times 10^{9} \mathrm{dyn} / \mathrm{cm}^{2}$ exists in the crystallized region [11]. The EB irradiation to as-grown polysilane does not promote the crystallization of the generated $\mathrm{Si}$ lines. Thermal annealing of EB irradiated polysilane at $800^{\circ} \mathrm{C}$ in $\mathrm{N}_{2}$ ambient for $2 \mathrm{hr}$ results in the crystallization as revealed by the reflection high-energy electron diffraction (RHEED) pattern of the EB-irradiated region (Fig. 4).

\subsection{Si pattern formation on polysilane by beam induced modification}

As demonstrated by structural analysis of beam-irradiated polysilane, a fine silicon pattern could be generated by using an EB lithography system. The nonirradiated part is easily oxidized in air and hence a Si pattern embedded in $\mathrm{SiO}_{2}$ can be obtained. The silicon line can be visualized by removing the nonirradiated, oxidized part of polysilane by dilute $(5 \%) \mathrm{HF}$ etching after EB direct writing. Under the conditions of an electron beam linewidth of $0.1 \mu \mathrm{m}$ and a dose of $20 \mathrm{mC} / \mathrm{cm}^{2}$ a Si line with a full width at half maximum (FWHM) of $0.12 \mu \mathrm{m}$ is obtained as shown in Fig. 5(a). Also, under the conditions of an electron beam irradiation region of $0.1 \times 0.1 \mu \mathrm{m}^{2}$ and a dose of $30 \mathrm{mC} / \mathrm{cm}^{2}$ Si pillars with a diameter of $0.14 \mu \mathrm{m}$ are obtained as illustrated in Fig. 5(b). The three-dimensional silicon network formation promoted by EB-induced hydrogen desorption is a key step in generating

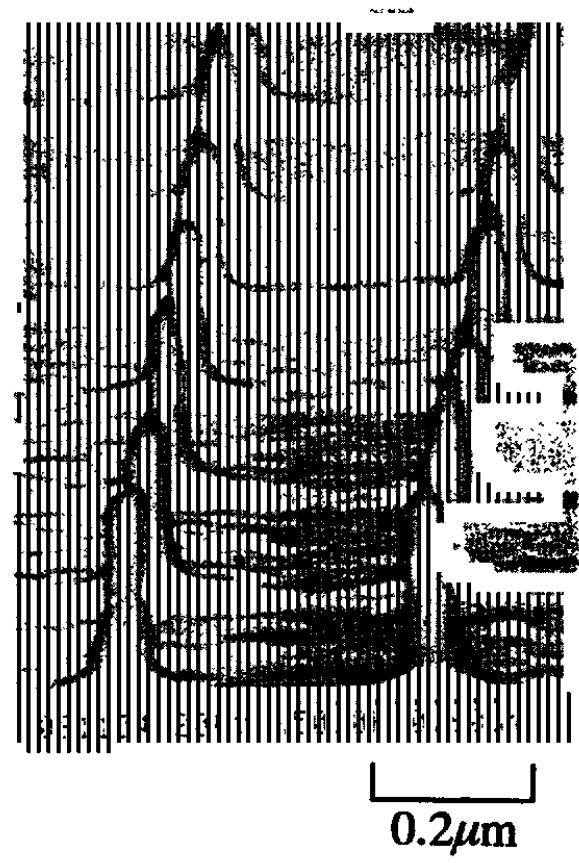

(a)

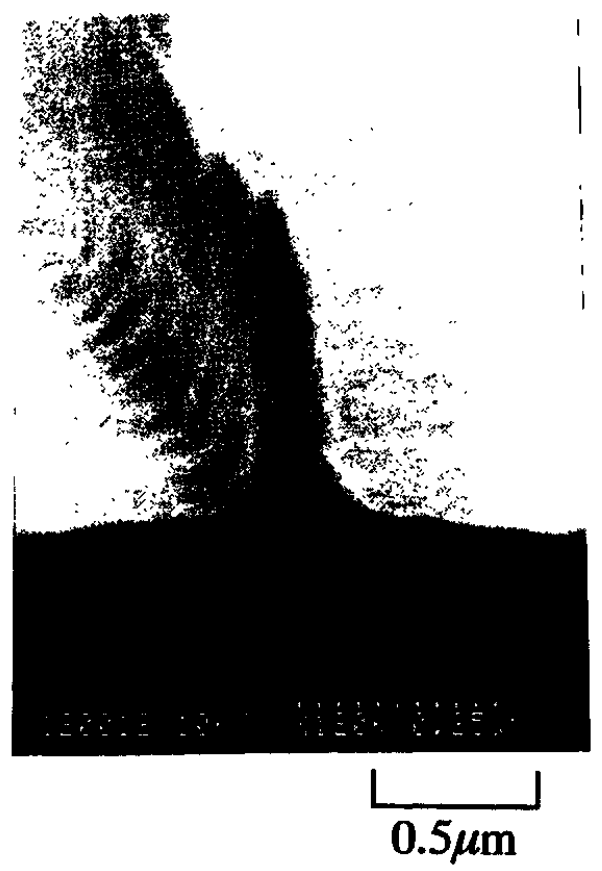

(b)

Fig. 5 Scanning electron micrographs of a Si line(a) and Si pillars(b) produced by EBinduced network formation in a polysilane film and subsequent removal of the nonirradiated, oxidized region by a dilute HF solution. 


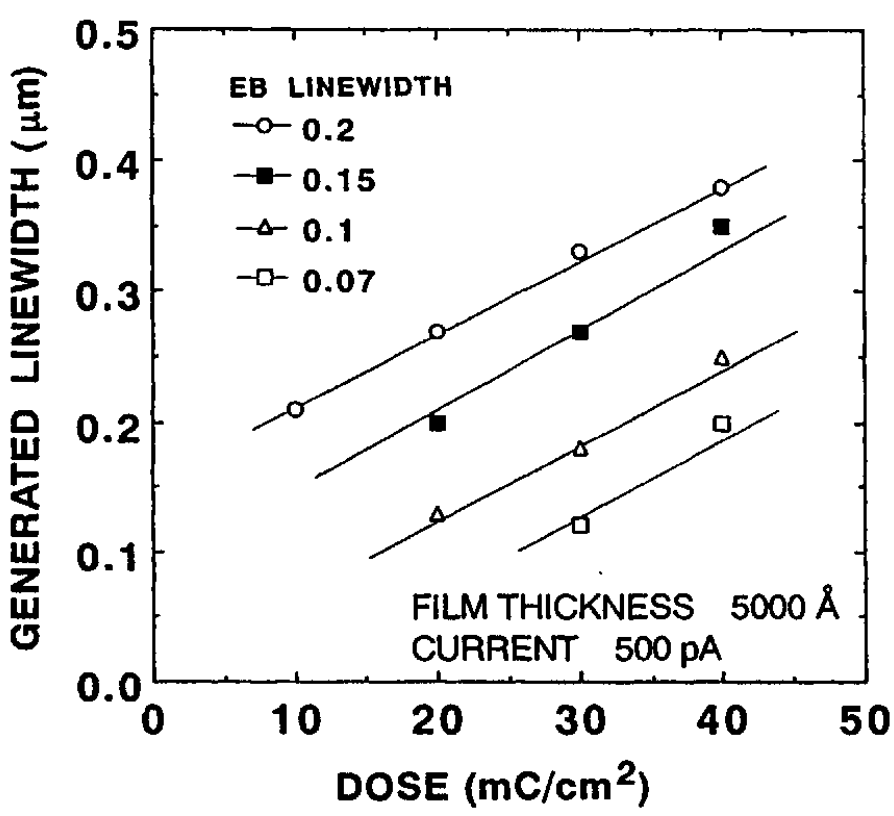

Fig. 6.Si linewidth generated from a polysilane film Fig. 7.Scanning electron micrograph of a poly-Si grown at $-110^{\circ} \mathrm{C}$ as a function of $\mathrm{EB}$ dose.

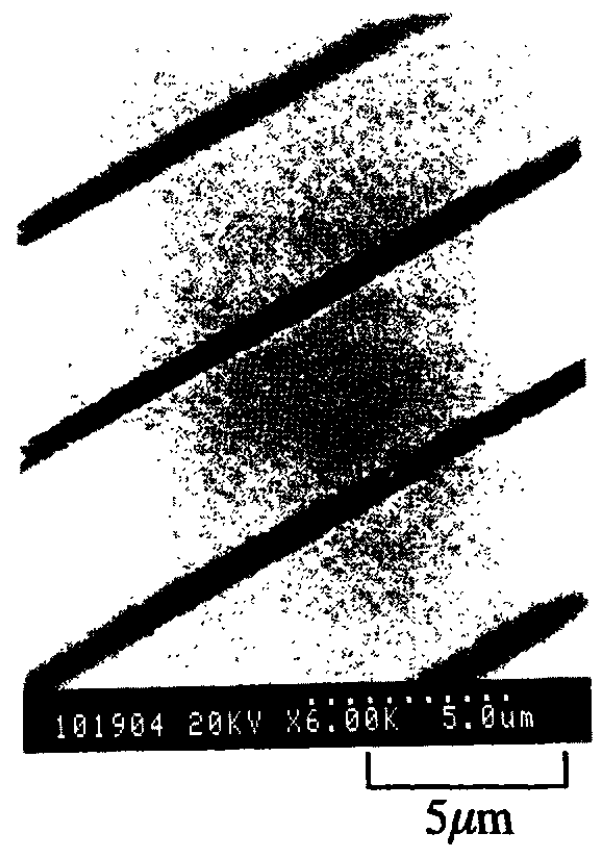

pattern obtained by irradiating the film through a $\mathrm{Cr}$ mask and subsequent dilute HF etch.

a fine silicon pattern. The generated linewidth determined from its FWHM depends on the EB dose, as shown in Fig. 6. The lower dose is better for preparing narrower lines, while there is the lowest dose limit to produce a stable silicon network.

Also, a fine polycrystalline $\mathrm{Si}$ pattern can be generated by laser irradiation to polysilane through a $\mathrm{Cr}$ mask and subsequent exposure of the film to air for the oxidation of nonirradiated region. The removal of the nonirradiated, oxidized region by dilute HF gives a poly-Si pattern with a linewidth of $1 \mu \mathrm{m}$ under the conditions of a mask pattern linewidth of $1 \mu \mathrm{m}$ and 1000 shots laser irradiation at a pulse energy of $10 \mathrm{~mJ} \bullet \mathrm{cm}^{-2} / \mathrm{shot}$ as illustrated in Fig. 7. The roughness observed at the pattern edges might reflect the spatially inhomogeneous Si network formation in polysilane. This problem can be solved by the improvement of structural homogeneity of an as-deposited polysilane film. Furthcr reduction of the pattern size will be achieved by using a 5 to 1 projection optics and a phase shifting mask instead of the contact-type Cr mask.

\section{CONCLUSIONS}

Very fine silicon lines with a width of about $0.12 \mu \mathrm{m}$ and pillars with a diameter of about 0.14 $\mu \mathrm{m}$ have been formed by electron beam direct writing on a polysilane thin film. It is shown that the irradiated part of polysilane can be crystallized to poly-Si by $800^{\circ} \mathrm{C}$ annealing. Also, the excimer- 
laser-induced desorption of the bonded hydrogen from polysilane promotes the three dimensional $\mathrm{Si}$ network formation and crystallization. The polysilicon pattern with a width of about $1 \mu \mathrm{m}$ is generated by the laser irradiation to polysilane through a mask and air exposure of the film followed by dilute $\mathrm{HF}$ etching.

\section{ACKNOWLEDGEMENT}

Part of this work has been carried out using an EB lithograpy system at Research Center for Integrated Systems, Hiroshima University.

\section{REFERENCES}

[1] H. G. Craighead and L. M. Schiavone: Appl. Phys. Lett. 48 (1986) 1748.

[2] A. Imai, H. Fukuda, T. Ueno and S. Okazaki: Jpn. J. Appl. Phys. 29 (1990) 2653.

[3] Y. Ochiai, M. Baba, H. Watanabe and S. Matsui: Jpn. J. Appl. Phys. 30 (1991) 3266.

[4] Timony W. Weidman and Ajey M. Joshii: Appl. Phys. Lett. 62 (1993) 372.

[5] H. Shin, S. Miyazaki, H. Ichihashi and M. Hirose: Proceedings of the International Seminar on Reactive Plasmas, Nagoya, 1991 (Organizing Committee of the International Seminar on Reactive Plasmas, Nagoya, 1991), p. 201.

[6] K. Okamoto, H. Shin, K. Shiba, S. Miyazaki and M. Hirose: Jpn. J. Appl. Phys. 31 (1992) 4441.

[7] S. Furukawa and N. Matsumoto: Phys. Rev. B 31 (1985) 2114.

[8] D. J. Wolford, J. A. Reimer and B. A. Scott: Appl. Phys. Lett. 42 (1983) 369.

[9] W. B. Pollard and G. Lucovsky: Phys. Rev. B 26 (1982) 3172.

[10] P. Vora, S. A. Solin and P. John, Phys. Rev. B, 29 (1984) 3423.

[11] Th. Englert, G. Abstreiter and J. Pontcharra, Solid-State Electron. 23 (1980) 31. 